\title{
Familial association between type 1 diabetes and other autoimmune and related diseases
}

\author{
K. Hemminki X. Li $\cdot$ J. Sundquist $\cdot$ K. Sundquist
}

Received: 12 February 2009 / Accepted: 28 May 2009/Published online: 20 June 2009

(C) Springer-Verlag 2009

\begin{abstract}
Aims/hypothesis In the era of genome-wide association studies, familial risks are used to estimate disease heritability and success in gene identification. We wanted to estimate associations between type 1 diabetes mellitus and 33 autoimmune and related diseases in parents, offspring, singleton siblings and twins.

Methods The availability of a Multigeneration Register in Sweden provides reliable access to families throughout the last century. The diseases in individual family members were obtained through linkage to the Hospital Discharge Register. Standardised incidence ratios (SIRs) were calculated as relative risks of contracting type 1 diabetes in family members of affected patients compared with those lacking affected family members.

Results Among a total of 450,899 patients, 21,168 were diagnosed with type 1 diabetes. Familial cases amounted to $10.3 \%$ of all type 1 diabetes patients. SIR for type 1 diabetes was 8.23 in offspring of affected parents, 11.92 in
\end{abstract}

K. Hemminki $(\bowtie)$

Division of Molecular Genetic Epidemiology,

German Cancer Research Center (DKFZ),

Im Neuenheimer Feld 580,

69120 Heidelberg, Germany

e-mail: k.hemminki@dkfz.de

K. Hemminki $\cdot$ K. Sundquist

Center for Family and Community Medicine, Karolinska Institute,

Huddinge, Sweden

$\mathrm{X} . \mathrm{Li} \cdot \mathrm{J}$. Sundquist

Center for Primary Health Care Research, Lund University,

Malmö, Sweden

J. Sundquist

Stanford Prevention Research Center,

Stanford University School of Medicine,

Stanford, CA, USA singleton siblings, 39.22 in multiplex families and 21.88 in twins; the calculated risk for monozygotic twins was 32.33 . Type 1 diabetes in offspring was associated with 13 diseases in parents, including Addison's disease (SIR 2.41), asthma (1.38), coeliac disease (2.73), Graves' disease/hyperthyroidism (1.86), Hashimoto disease/hypothyroidism (2.35), pernicious anaemia (3.09), primary biliary cirrhosis (3.63), rheumatoid arthritis (2.12), sarcoidosis (1.62), systemic lupus erythematosus (2.04), ulcerative colitis (1.23) and Wegener's granulomatosis (2.12).

Conclusions/interpretation The concordant familial risks for type 1 diabetes were high and the calculated risk for multiplex families and monozygotic twins may be explained by epistatic gene $\times$ gene or gene $\times$ environment interactions. Familial associations with several autoimmune and related diseases suggest genetic sharing and challenge to gene identification.

Keywords Autoimmunity · Diabetes · Disease genes · Genome scans $\cdot$ Heritability

\author{
Abbreviations \\ ICD International Classification of Diseases \\ SIR Standardised incidence ratio
}

\section{Introduction}

Type 1 diabetes mellitus is an early-onset autoimmune disease in which immune response is directed against the insulin-producing beta cells of the pancreas, resulting in insulin dependence. The disease is thought to be triggered in susceptible individuals by environmental, demographic and ethnic factors, including parental country of origin, and by physiological factors and medical conditions such as 
enteroviral infections, old parental age at birth, preeclampsia, cesarean section delivery, increased birthweight, early exposure to cows' milk and high rate of postnatal growth [1-3]. Family history is an important risk factor shown in twins and singleton siblings [4-6]. The sibling relative risk is cited to be 15 but it depends critically on the age of onset and probably on the background incidence of the disease [7-10]. The HLA region with several protective and predisposing alleles is the main genetic determinant of type 1 diabetes risk, with a total of 15 genes or loci associated to date with type 1 diabetes risk [11-14]. According to a recent calculation, the HLA region accounts for $41 \%$ of familial clustering of type 1 diabetes, adding up to $48 \%$ in combination with all the recently detected loci [15]. This percentage is uniquely high among complex diseases [11].

Genetic and epidemiological data indicate that certain autoimmune diseases aggregate in type 1 diabetes families $[10,11,14-25]$. Reported associated autoimmune and related diseases include coeliac disease, multiple sclerosis, rheumatoid arthritis and autoimmune polyendocrine syndrome [14, 21, 26-28].

The availability of a Multigeneration Register in Sweden provides reliable access to health data of families throughout the last century. This Register has been extensively used to study hospitalised diseases, including familial autoimmune diseases, through linkage to the Hospital Discharge Register [21, 22, 29-32]. In the present article we studied familial risks for type 1 diabetes among parents and offspring, and singleton siblings and twins. Both concordant (type 1 diabetes in families) and discordant associations (type 1 diabetes and other diseases in families) were studied, together with any of 33 other autoimmune and related diseases. These 33 diseases were autoimmune, inflammatory and related conditions that were selected because of aetiological hypothesis or previous association studies. Because many autoimmune diseases show marked sex preferences in prevalence, sex-specific familial risks were also analysed [26]. With a total patient population of 450,899 , of whom 21,168 were diagnosed with type 1 diabetes, this is the largest family study published on these diseases; the associations between type 1 diabetes and many of the discordant diseases have never been reported before. The advantage of the present study is that all the results emanate from a single population of medically confirmed cases in a country of high medical standard and reasonably uniform diagnostics.

\section{Methods}

The research database used for this study, the autoimmune disease database, is a subset of the national MigMed database at Center for Primary Health Care Research,
Malmö, Lund University. The MigMed database was compiled using data from several national Swedish registers provided by Statistics Sweden, including the Multigeneration Register in which persons (second generation) born in Sweden from 1932 onwards were registered shortly after birth and are linked to their parents (first generation) through the individually unique person number. In this Register, a child is registered with both parents as triplets, enabling families to be constructed by considering common mothers or fathers for the offspring [33, 34]. Sibships could be defined for the second and any subsequent generation. National Census Data (1960-1990) and the Swedish population register (1990-2001) were incorporated into the database to obtain information on individuals' socioeconomic status. Dates of hospitalisation for autoimmune diseases were obtained during the study period from the Swedish Hospital Discharge Register for the years 1964 to 2007. Patients registered for hospitalisation stayed at least 1 night in the hospital, usually in wards with specialists; the Register does not include outpatients or patients at healthcare centres. Diagnoses were reported according to the different versions of the International Classification of Diseases (ICD), classified into 34 autoimmune groups of diseases. Type 1 diabetes was defined through first hospitalisation before age 20 years, partially, because type 1 diabetes was not defined as an independent entity until ICD-9, i.e. 1987. All linkages were performed using the national ten-digit civic identification number that is assigned to each person in Sweden for his or her lifetime. This number was replaced by a serial number for each person in order to provide anonymity and to check that each individual was only entered once for his or her first hospitalisation for an autoimmune disease. The total population, born between 1860 and 2007, was 12 million. The study was limited to offspring of whom both parents were known, which was some $98 \%$ of the population born in Sweden.

Person-years were calculated from start of follow-up on 1 January 1964 until hospitalisation for the first autoimmune disease, death, emigration or closing date on 31 December 2007. Age-specific incidence rates were calculated for the whole follow-up period, divided into five 5 -year periods. Standardised incidence ratios (SIRs) were calculated as the ratio of observed $(\mathrm{O})$ to expected $(\mathrm{E})$ number of cases. The expected number of cases was calculated for age (5-year groups), sex, period (5-year groups), region and socioeconomic status-specific standard incidence rates. Familial risks were calculated for men and women (in the second generation) with parents as probands, singleton siblings or twins affected with concordant (same) or discordant (different) autoimmune disease, compared with men and women whose relatives were not affected by these conditions. For the calculation of SIRs in offspring 


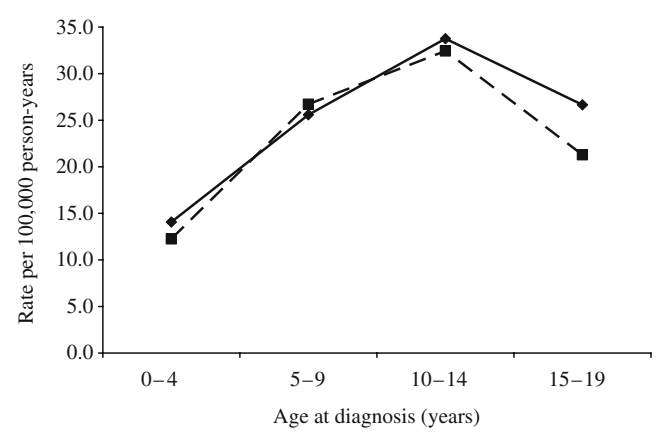

Fig. 1 Age-specific hospitalisations for type 1 diabetes in men (diamonds) and women (squares)

using parental probands, person-years were accumulated for the offspring of affected parents and counted separately for offspring of unaffected parents. If the numbers of children were less in the families of type 1 diabetic patients than in those of healthy individuals [35], the numbers of personyears would also be smaller without bias. Risks for sibling were calculated using the cohort methods as described [36]. In this method, all siblings in families of two or more affected sibling contribute cases and these are compared with single-case families using the described person-year calculation; the method is not sensitive to family size. In rare families where more than two siblings were affected (of 1,432 affected singleton siblings, 673 were from families of two affected, 26 from families of three affected and two from families of four or more affected siblings), each was counted as an individual patient. We do not have data on zygosity. Instead, the proportion of monozygotic twins can be estimated using Weinberg's difference method, which uses the fact that all different-sex twins are dizygotic [37, 38]. Confidence intervals (95\% CI and 99\% CI) were calculated assuming a Poisson distribution and were adjusted for dependence between the sibling pairs [36].

\section{Results}

The total number of type 1 diabetes patients diagnosed before age 20 years was 21,168 . The highest hospitalisation rates for type 1 diabetes were in the 10 to 14 years age group and were somewhat higher for boys than for girls (Fig. 1), in agreement with data from Finland and Sweden $[3,9]$; the male excess was significant at $p<0.001$ in the youngest and the oldest age groups considered, and for all combined, but the relative rate was only 1.08 (95\% CI 1.05-1.11). Also, the familial risks for siblings were identical for men and women, i.e. 12.38 and 12.20, respectively (Table 1). SIRs decreased from 17.88 at diagnostic age 0 to 4 years to 10.73 at diagnostic age 15 to 19 years.

The total number of patients diagnosed with any of the 34 autoimmune diseases was 450,899 . The largest groups were patients diagnosed with asthma at 145,041 and those with rheumatoid arthritis at 51,394, followed by Graves' disease/ hyperthyroidism at 34,879 and ulcerative colitis at 28,640 . The numbers of cases for each disease in the offspring population are shown in Table 2. Familial risks for type 1 diabetes in offspring are shown in Table 2 according to mutually exclusive proband categories, i.e. parent only, singleton sibling only, parent and sibling (multiplex), and twin. The total number of familial type 1 diabetes cases in offspring was 2,171 (in parents and offspring), 10.3\% of all type 1 diabetes patients. The SIR for offspring was 8.23 when a parent was diagnosed with type 1 diabetes. The SIR for type 1 diabetes was also increased when a parent was diagnosed with 13 of the 33 diseases studied, including Addison's disease (2.41), asthma (1.31), coeliac disease (2.73), Graves' disease/hyperthyroidism (1.86), Hashimoto's disease/hypothyroidism (2.35), pernicious anaemia (3.09), primary biliary cirrhosis (3.63), rheumatoid arthritis (2.12), sarcoidosis (1.62), systemic lupus erythematosus (2.04), ulcerative colitis (1.23) and Wegener's granulomatosis

Table 1 SIR for diabetes type 1 in singleton siblings by age at diagnosis

\begin{tabular}{|c|c|c|c|c|c|c|c|c|c|}
\hline \multirow{2}{*}{$\begin{array}{l}\text { Age at } \\
\text { diagnosis } \\
\text { (years) }\end{array}$} & \multicolumn{3}{|l|}{ Men } & \multicolumn{3}{|l|}{ Women } & \multicolumn{3}{|l|}{ All } \\
\hline & $\begin{array}{l}\text { Observed } \\
\text { cases }(n)\end{array}$ & SIR & $95 \% \mathrm{CI}$ & $\begin{array}{l}\text { Observed } \\
\text { cases }(n)\end{array}$ & SIR & $95 \% \mathrm{CI}$ & $\begin{array}{l}\text { Observed } \\
\text { cases }(n)\end{array}$ & SIR & $95 \% \mathrm{CI}$ \\
\hline $0-4$ & 153 & $18.65^{\mathrm{a}, \mathrm{b}}$ & $11.18-30.90$ & 117 & $16.98^{\mathrm{a}, \mathrm{b}}$ & $9.93-28.78$ & 270 & $17.88^{\mathrm{a}, \mathrm{b}}$ & $11.18-28.50$ \\
\hline $5-9$ & 228 & $13.22^{\mathrm{a}, \mathrm{b}}$ & $8.17-21.28$ & 196 & $11.28^{\mathrm{a}, \mathrm{b}}$ & $6.90-18.34$ & 424 & $12.24^{\mathrm{a}, \mathrm{b}}$ & 7.85-19.04 \\
\hline $10-14$ & 258 & $11.13^{\mathrm{a}, \mathrm{b}}$ & $6.94-17.78$ & 245 & $11.72^{\mathrm{a}, \mathrm{b}}$ & $7.28-18.78$ & 503 & $11.41^{\mathrm{a}, \mathrm{b}}$ & $7.38-17.60$ \\
\hline $15-19$ & 161 & $10.09^{\mathrm{a}, \mathrm{b}}$ & $6.07-16.65$ & 132 & $11.62^{\mathrm{a}, \mathrm{b}}$ & $6.88-19.50$ & 293 & $10.73^{\mathrm{a}, \mathrm{b}}$ & $6.74-17.01$ \\
\hline All & 800 & $12.38^{\mathrm{a}, \mathrm{b}}$ & $8.16-18.77$ & 690 & $12.20^{\mathrm{a}, \mathrm{b}}$ & $8.00-18.60$ & 1490 & $12.30^{\mathrm{a}, \mathrm{b}}$ & $8.26-18.30$ \\
\hline
\end{tabular}

${ }^{\text {a }} 95 \%$ CI does not include 1.00

b $99 \%$ CI does not include 1.00 


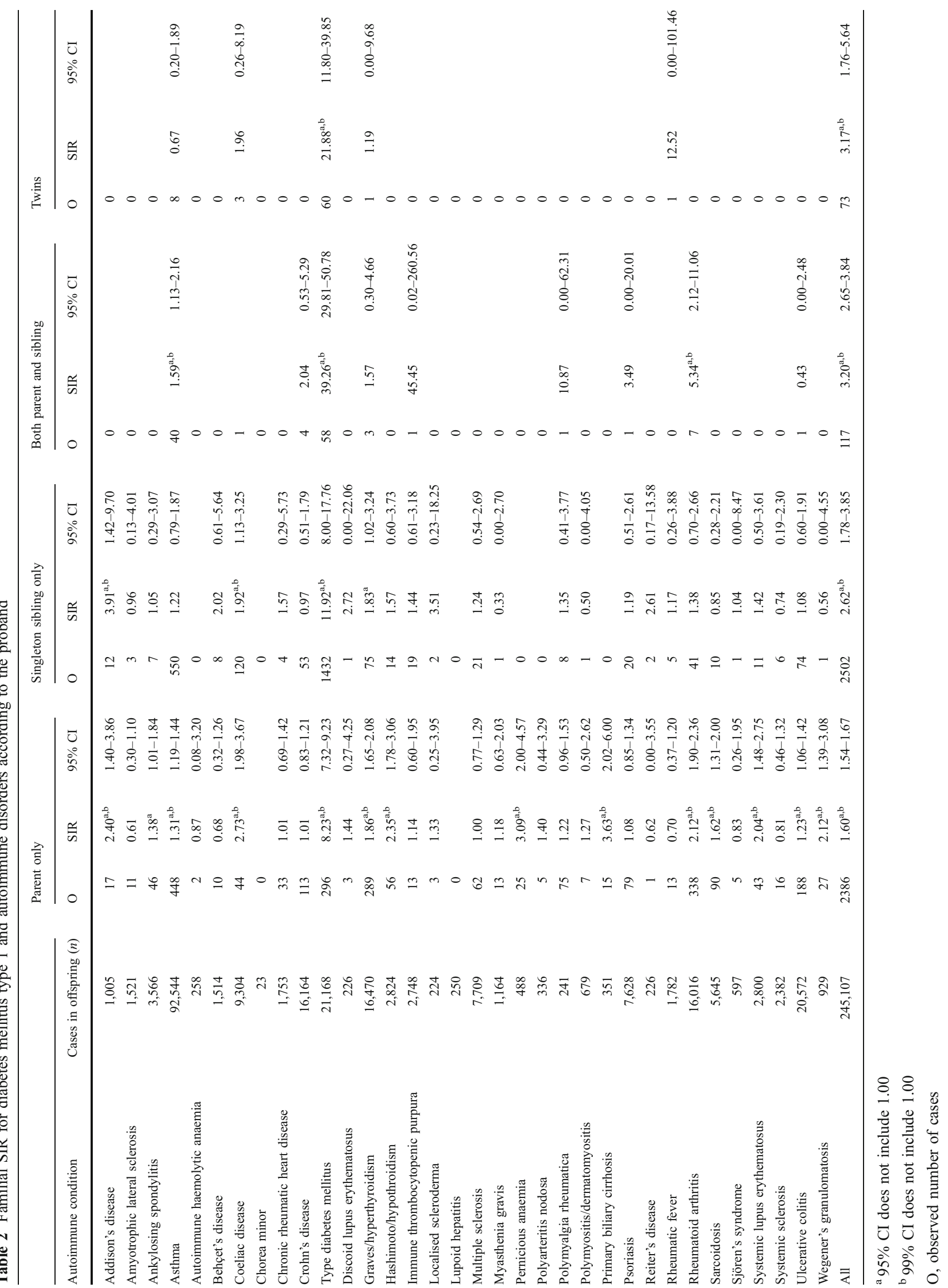


(2.12). The risk was 1.60 when a parent presented with any autoimmune disease and related conditions.

Among singleton siblings the SIR for type 1 diabetes was 11.92; note that this SIR is somewhat lower than the one in Table 1 because the present data refer to siblingsonly families (1,432 vs 1,490, as 58 offspring belonged to multiplex families with 32 affected parents, combined 90 affected individuals). As discordant diseases, only Addison's disease, coeliac disease and Graves' disease/hyperthyroidism were associated with type 1 diabetes (Table 2). When a parent and a sibling were diagnosed with type 1 diabetes (multiplex families), the SIR for further siblings was $39.26 ; 87$ patients $(0.4 \%$ of the type 1 diabetes population) belonged to the multiplex families group and 117 belonged to multiplex families with any autoimmune disease. SIRs for type 1 diabetes were also increased when a parent and a sibling were diagnosed with asthma and rheumatoid arthritis. Only concordant type 1 diabetes (21.88) was significant among twins.

Sex-specific familial risks for type 1 diabetes are shown in Table 3. The offspring of affected fathers had a higher risk of type 1 diabetes (11.87 in sons, 10.97 in daughters) than the offspring of affected mothers (7.36 in sons, 8.15 in daughters). For discordant associations, sex-specific case numbers tended to be small and thus none were formally significant (95\% CIs overlapped). However, the associations between type 1 diabetes and primary biliary cirrhosis, ulcerative colitis and Wegener's granulomatosis were increased only in offspring of affected mothers, whereas those between type 1 diabetes and pernicious anaemia were increased in offspring of affected fathers; the association between type 1 diabetes and coeliac disease was only significant in daughters.

The twin data were analysed in more detail in Table 4. The data show no large difference by sex. Only three twin pairs were of different sex, i.e. dizygotic; the SIR for these was somewhat lower than that for singleton siblings in Table 2. Using Weinberg's difference method $[37,38]$ we calculated the risk for monozygotic twins to be 32.33 . Table 4 also shows the risks for singleton siblings by age difference defined as less or more than 5 years. No difference was observed for age difference or sex.

\section{Discussion}

Several of the type 1 diabetes susceptibility genes identified to date also predispose to other autoimmune diseases. A familial aggregation of type 1 diabetes with some autoimmune diseases has also been shown. However, to our knowledge this is the first population-level attempt to assess familial risks for type 1 diabetes and a large number of autoimmune and related diseases using unified data $[10,11,14,21,24,25,27,28]$. The use of hospitalised cases offers advantages and disadvantages for aetiological studies. Hospitalisation may involve selection for diseases for which not all patients are hospitalised; thus family members of hospitalised cases may preferentially seek hospitalisation and hospitalised cases may be more severe than those treated in open care. For example, the low number of Hashimoto's disease/hypothyroidism cases compared with Graves' disease/hypothyroidism cases is likely to be due to a lower degree of hospitalisation for the former condition [39, 40]. There are no overall estimates as to what degree patients with various diagnoses are hospitalised. A fair assumption would be that severe and life-threatening conditions invariably lead to hospitalisation as opposed to conditions that can be treated in open care, such as uncomplicated asthma or hypothyroidism. However, this should not be a large problem in the present study of type 1 diabetes patients diagnosed before age 20 years, because apparently all diabetic children and youngsters are hospitalised in Sweden [21]. This patient population may include a small number of other types of early-onset diabetes, such as maturity-onset diabetes of the young, type 2 diabetes and rare syndromatic forms of diabetes; however, collectively these are estimated to account for $5 \%$ of children seen in diabetes clinics [41].

Although diagnostic accuracy for type 1 diabetes is probably high, it may not be so for the other 33 diseases covered and, unfortunately, related data are lacking for many diseases. Crohn's disease and ulcerative colitis are diseases for which diagnostic accuracy for hospitalised patients has been estimated in Sweden by comparing the hospital discharge data with regional registers and with individually reviewed patient data; the disease concordance was $96 \%$ [42]. A study on hospitalised rheumatoid arthritis patients found that some $90 \%$ of the patients fulfilled the criteria of the American College of Rheumatology [43]. According to a study of coeliac disease, a correct diagnosis was used in over $85 \%$ of discharged patients [21, 44]. A close to $90 \%$ diagnostic accuracy has been reported for patients discharged with Wegener's granulomatosis [45]. With poor diagnostic accuracy, any effects would be expected to regress towards null, which appeared not to be the case with the present results.

The present results confirm the very high familial risk for type 1 diabetes and the high proportion of familial cases, $10.3 \%$, which is somewhat less than in a UK study [8]. Somewhat higher familial risks were found for offspring of affected fathers compared with those of affected mothers, but the difference was not as large as observed in some but not all earlier studies $[6,7,26]$. The risk depended on diagnostic age, and in the youngest group, i.e. those diagnosed before age 5 years, the risk was 17.88 . The age of onset correlated with the presence of HLA risk 


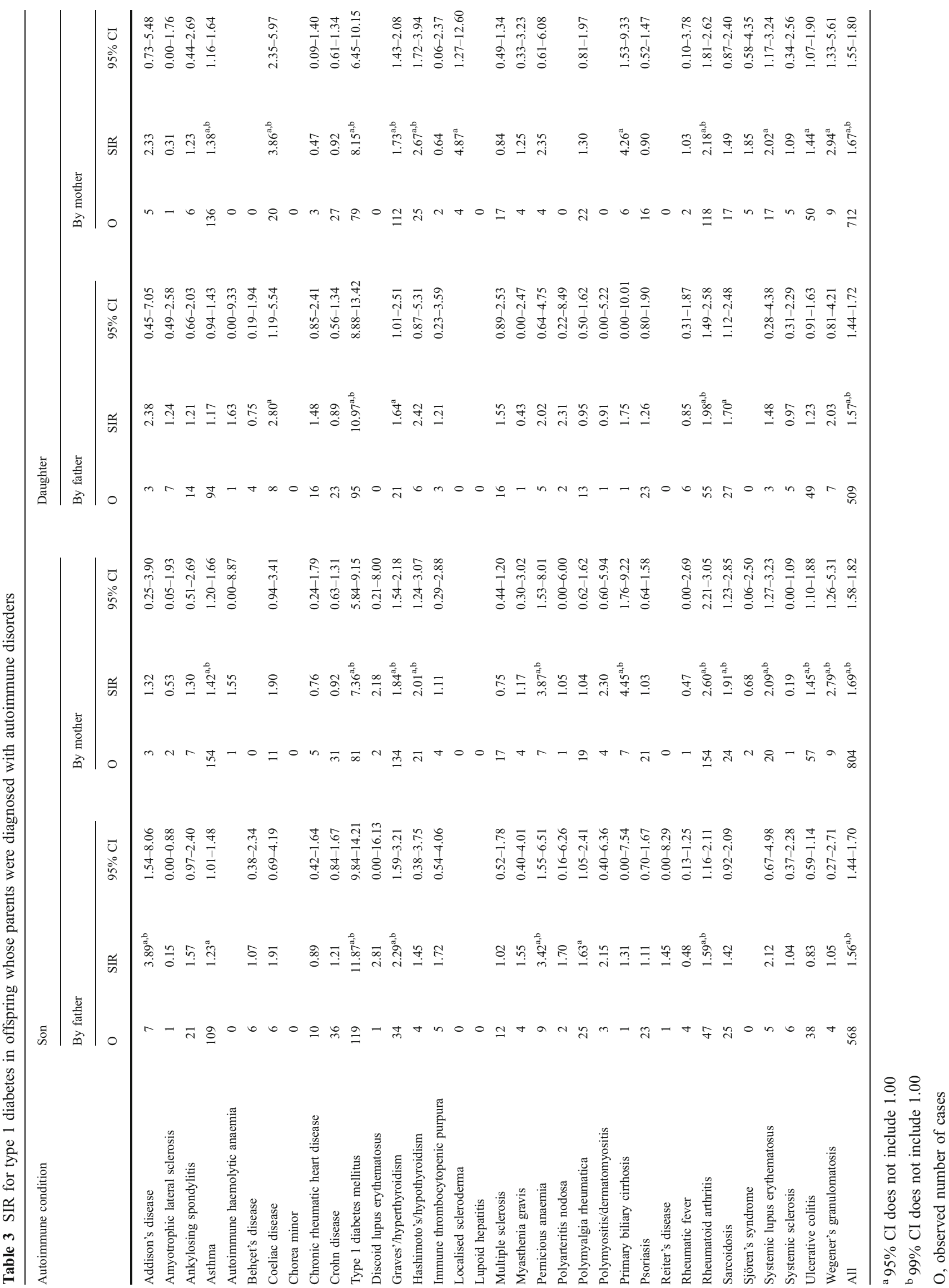


Table 4 SIR for type 1 diabetes mellitus by sex in twins and by age difference in singleton siblings

\begin{tabular}{|c|c|c|c|c|c|c|c|c|c|}
\hline \multirow[t]{2}{*}{ Variables } & \multicolumn{3}{|l|}{ Men } & \multicolumn{3}{|c|}{ Women } & \multicolumn{3}{|l|}{ All } \\
\hline & $\mathrm{O}$ & SIR & $95 \% \mathrm{CI}$ & $\mathrm{O}$ & SIR & $95 \% \mathrm{CI}$ & $\mathrm{O}$ & SIR & $95 \% \mathrm{CI}$ \\
\hline \multicolumn{10}{|l|}{ Sex in twins } \\
\hline Men & 34 & $30.63^{\mathrm{a}, \mathrm{b}}$ & $14.99-60.58$ & 3 & 7.32 & $0.98-30.62$ & 37 & $24.34^{\mathrm{a}, \mathrm{b}}$ & $12.11-47.48$ \\
\hline Women & 3 & 5.82 & $0.78-24.36$ & 20 & $28.31^{\mathrm{a}, \mathrm{b}}$ & $12.21-61.95$ & 23 & $18.82^{\mathrm{a}, \mathrm{b}}$ & $8.43-40.00$ \\
\hline \multicolumn{10}{|c|}{ Age difference in singleton siblings } \\
\hline$<5$ years & 442 & $12.88^{\mathrm{a}, \mathrm{b}}$ & $8.28-20.00$ & 381 & $12.77^{\mathrm{a}, \mathrm{b}}$ & $8.14-19.96$ & 823 & $12.83^{\mathrm{a}, \mathrm{b}}$ & $8.46-19.43$ \\
\hline$\geq 5$ years & 358 & $11.82^{\mathrm{a}, \mathrm{b}}$ & $7.51-18.53$ & 309 & $11.58^{\mathrm{a}, \mathrm{b}}$ & $7.30-18.30$ & 667 & $11.70^{\mathrm{a}, \mathrm{b}}$ & $7.66-17.86$ \\
\hline
\end{tabular}

${ }^{\text {a } 95 \% ~ C I ~ d o e s ~ n o t ~ i n c l u d e ~} 1.00$

b $99 \%$ CI does not include 1.00

$\mathrm{O}$, observed number of cases

haplotypes in affected individuals [7-9]. There was a minor difference in risk for offspring of affected parents (8.23) and for singleton siblings (11.92), which is most likely to be due to the higher age of the diagnosed parents, thus leaving little scope for possible recessive inheritance. Shared childhood environmental effects would probably cause higher risks for siblings close in age compared with those with a large age difference. No indication to that effect was observed, nor have twin studies found evidence of shared environmental effects. The SIR for twins of unknown zygosity was 21.88 , which was clearly higher than that for multiple sclerosis (9.09) or rheumatoid arthritis (6.48), which we have recently assessed in this same population $[32,46]$. The calculated type 1 diabetes risk for 48 monozygotic twins $(0.2 \%$ of all patients $)$ was 32.33 , which was clearly higher than predicted from additive genetic effects calculated from the SIR of singleton siblings (SIR 11.92, excess risks $11.92-1.00=10.92$; calculated for monozygotic twins: $10.92 \times 2=21.84$, which when added to the background rate of 1.00 amounts to 22.84). A possible interpretation would be epistatic interaction of two or more genes or gene $\times$ environment interactions [47], which may fit with the detected plethora of low-penetrance genes acting in different pathways of immune signalling [14].

Another measure of high heritability for type 1 diabetes was the remarkably high SIR of 39.26 in multiplex families which included $0.4 \%$ of the type 1 diabetes population. Multiplex families together with concordant monozygotic twins made up the high-risk population, which constituted $0.6 \%$ of all patients and had SIRs between 30 and 40 . It can be shown that such high familial risks can only be caused by rare risk alleles of very high genotype relative risk or by strong epistatic interactions $[48,49]$, for which some rare HLA haplotype variants qualify $[6,15]$. However, even for the remaining $10 \%$ of the familial type 1 diabetes population characterised by a high sibling risk of 11.92 , interacting variants probably need to be invoked, because the newly detected low-penetrance non-HLA loci only marginally contribute to the familial aggregation of type 1 diabetes [15].

A total of 13 parental autoimmune and related conditions were associated with type 1 diabetes in offspring whose SIRs were over 3.00 when parents were diagnosed with pernicious anaemia and primary biliary cirrhosis. Considering the number of comparisons carried out, some positive results may turn out to be due to chance. Similarly, we would have expected some significant protective effects by chance, but none were found. Some findings were replicated among siblings, including Addison's and coeliac diseases, and Graves' disease/hyperthyroidism, and some were replicated in 'multiple families' including asthma and rheumatoid arthritis, the latter with a high SIR of 5.34. The clustering of type 1 diabetes, Addison's disease and autoimmune thyroid disease is known as autoimmune polyendocrine syndrome type 2 [26, 28]. In sex-specific discordant analyses case numbers were small and no significant sex-related differences were demonstrated. Nevertheless associations between type 1 diabetes and primary biliary cirrhosis, ulcerative colitis and Wegener's granulomatosis were increased only in offspring of affected mothers whereas those between type 1 diabetes and pernicious anaemia were increased in offspring of affected fathers. The association between type 1 diabetes and coeliac disease was only significant in daughters. However, larger study populations would be required in order to demonstrate true sex-specific effects.

Genetic association studies have shown shared risk alleles for several autoimmune conditions, particularly for the HLA-DRB1 gene. However, only a limited number of other genes show susceptibility to type 1 diabetes and the diseases studied here. One example is CTLA4, a shared susceptibility gene for type 1 diabetes and autoimmune thyroid disease [14]. Even for diseases that have shown to be linked to risk alleles associated with type 1 diabetes, 
including coeliac disease and rheumatoid arthritis, the contribution to the observed familial association may not be large, because even relatively common low-risk alleles tend to explain little of the familial clustering of a disease $[18,50]$. Thus the present data suggest that in further genetic studies new genes and causative variants of the implicated loci will be found, which will help to explain some of the described associations. Reliable familial risks are a helpful roadmap in guiding genetic studies and in measuring their success in terms of the explained familial risk.

Acknowledgements Supported by The Swedish Council for Working Life and Social Research and the Swedish Research Council. The database used was created by linking registers maintained at Statistics Sweden and The National Board of Health.

Duality of interest The authors declare that there is no duality of interest associated with this manuscript.

\section{References}

1. Knip M, Veijola R, Virtanen SM, Hyoty H, Vaarala O, Akerblom HK (2005) Environmental triggers and determinants of type 1 diabetes. Diabetes 54(Suppl 2):S125-S136

2. Soltesz G, Patterson CC, Dahlquist G (2007) Worldwide childhood type 1 diabetes incidence-what can we learn from epidemiology? Pediatr Diabetes 8(Suppl 6):6-14

3. Hjern A, Soderstrom U (2008) Parental country of birth is a major determinant of childhood type 1 diabetes in Sweden. Pediatr Diabetes 9:35-39

4. Field LL (2002) Genetic linkage and association studies of type 1 diabetes: challenges and rewards. Diabetologia 45:21-35

5. Hyttinen V, Kaprio J, Kinnunen L, Koskenvuo M, Tuomilehto J (2003) Genetic liability of type 1 diabetes and the onset age among 22,650 young Finnish twin pairs: a nationwide follow-up study. Diabetes 52:1052-1055

6. Hirschhorn J (2003) Genetic epidemiology of type 1 diabetes. Pediatr Diabetes 4:87-100

7. Gillespie KM, Gale EA, Bingley PJ (2002) High familial risk and genetic susceptibility in early onset childhood diabetes. Diabetes 51:210-214

8. Lambert AP, Gillespie KM, Thomson G et al (2004) Absolute risk of childhood-onset type 1 diabetes defined by human leukocyte antigen class II genotype: a population-based study in the United Kingdom. J Clin Endocrinol Metab 89:4037-4043

9. Harjutsalo V, Podar T, Tuomilehto J (2005) Cumulative incidence of type 1 diabetes in 10,168 siblings of Finnish young-onset type 1 diabetic patients. Diabetes 54:563-569

10. Huber A, Menconi F, Corathers S, Jacobson EM, Tomer Y (2008) Joint genetic susceptibility to type 1 diabetes and autoimmune thyroiditis: from epidemiology to mechanisms. Endocr Rev 29:697-725

11. The Wellcome Trust Case-Control Consortium (2007) Genomewide association study of 14,000 cases of seven common diseases and 3, 000 shared controls. Nature 447:661-683

12. Ounissi-Benkalha H, Polychronakos C (2008) The molecular genetics of type 1 diabetes: new genes and emerging mechanisms. Trends Mol Med 14:268-275

13. Cooper JD, Smyth DJ, Smiles AM et al (2008) Meta-analysis of genome-wide association study data identifies additional type 1 diabetes risk loci. Nat Genet 40:1399-1401
14. Zhernakova A, van Diemen CC, Wijmenga C (2009) Detecting shared pathogenesis from the shared genetics of immune-related diseases. Nat Rev Genet 10:43-55

15. Todd JA, Walker NM, Cooper JD et al (2007) Robust associations of four new chromosome regions from genome-wide analyses of type 1 diabetes. Nat Genet 39:857-864

16. Broadley SA, Deans J, Sawcer SJ, Clayton D, Compston DA (2000) Autoimmune disease in first-degree relatives of patients with multiple sclerosis. A UK survey. Brain 123:1102-1111

17. Cho JH, Weaver C (2007) The genetics of inflammatory bowel disease. Gastroenterology 133:1327-1339

18. Barrett JC, Hansoul S, Nicolae DL et al (2008) Genome-wide association defines more than 30 distinct susceptibility loci for Crohn's disease. Nat Genet 40:955-962

19. Criswell LA, Pfeiffer KA, Lum RF et al (2005) Analysis of families in the multiple autoimmune disease genetics consortium (MADGC) collection: the PTPN22 620W allele associates with multiple autoimmune phenotypes. Am J Hum Genet 76:561-571

20. Fisher SA, Tremelling M, Anderson CA et al (2008) Genetic determinants of ulcerative colitis include the ECM1 locus and five loci implicated in Crohn's disease. Nat Genet 40:710-712

21. Ludvigsson JF, Ludvigsson J, Ekbom A, Montgomery SM (2006) Celiac disease and risk of subsequent type 1 diabetes: a general population cohort study of children and adolescents. Diabetes Care 29:2483-2488

22. Elfstrom P, Montgomery SM, Kampe O, Ekbom A, Ludvigsson JF (2008) Risk of thyroid disease in individuals with celiac disease. J Clin Endocrinol Metab 93:3915-3921

23. Hemminki K, Bermejo JL, Forsti A (2008) Genetics of inflammatory bowel disease: population aspects. Gastroenterology 134:2190-2191

24. Forabosco P, Bouzigon E, Ng MY et al (2009) Meta-analysis of genome-wide linkage studies across autoimmune diseases. Eur J Hum Genet 17:236-243

25. Jacobson EM, Tomer Y (2007) The genetic basis of thyroid autoimmunity. Thyroid 17:949-961

26. Dorman JS, Steenkiste AR, O'Leary LA, McCarthy BJ, Lorenzen T, Foley TP (2000) Type 1 diabetes in offspring of parents with type 1 diabetes: the tip of an autoimmune iceberg? Pediatr Diabetes 1:17-22

27. Nielsen NM, Westergaard T, Frisch M et al (2006) Type 1 diabetes and multiple sclerosis: A Danish population-based cohort study. Arch Neurol 63:1001-1004

28. Betterle C, Zanchetta R (2003) Update on autoimmune polyendocrine syndromes (APS). Acta Biomed 74:9-33

29. Landgren O, Engels EA, Pfeiffer RM et al (2006) Autoimmunity and susceptibility to Hodgkin lymphoma: a population-based case-control study in Scandinavia. J Natl Cancer Inst 98:13211330

30. Hemminki K, Li X, Sundquist K, Sundquist J (2008) Familial risks for common diseases: etiologic clues and guidance to gene identification. Mutat Res Rev 658:247-258

31. Sundquist K, Martinéus J, Li X, Hemminki K, Sundquist J (2008) Concordant and discordant associations between rheumatoid arthritis, systemic lupus erythematosus and ankylosing spondylitis based on all hospitalisations in Sweden between 1973 and 2004. Rheumatology (Oxford) 47:1199-1202

32. Hemminki K, Li X, Sundquist J, Sundquist K (2009) Familial associations of rheumatoid arthritis with autoimmune disorders and related conditions. Arthritis Rheum 60:661-668

33. Hemminki K, Vaittinen P (1997) Familial cancer in Sweden: population-based study. Int J Oncol 11:273-280

34. Hemminki K, Li X, Plna K, Granström C, Vaittinen P (2001) The nation-wide Swedish Family-Cancer Database: updated structure and familial rates. Acta Oncol 40:772-777

35. Gafvels C, Borjesson B, Lithner F (1991) The social consequences of insulin-treated diabetes mellitus in patients 20-50 years of 
age. An epidemiological case-control study. Scand J Soc Med 19:86-93

36. Hemminki K, Vaittinen P, Dong C, Easton D (2001) Sibling risks in cancer: clues to recessive or X-linked genes? $\mathrm{Br} \mathrm{J}$ Cancer $84: 388-391$

37. Vogel F, Motulsky A (1996) Human genetics: problems and approaches. Springer, Heidelberg

38. Hemminki K, Li X, Sundquist K, Sundquist J (2007) Familial risks for asthma among twins and other siblings based on hospitalizations in Sweden. Clin Exp Allergy 37:1320-1325

39. Cooper D (2003) Hyperthyroidism. Lancet 362:459-468

40. Roberts CG, Ladenson PW (2004) Hypothyroidism. Lancet 363:793-803

41. Barrett T (2007) Differential diagnosis of type 1 diabetes: which genetic syndromes need to be considered? Pediatr Diabetes Suppl 6:15-23

42. Askling J, Brandt L, Lapidus A et al (2005) Risk of haematopoietic cancer in patients with inflammatory bowel disease. Gut 54:617-622

43. Askling J, Fored CM, Geborek P et al (2006) Swedish registers to examine drug safety and clinical issues in RA. Ann Rheum Dis $65: 707-712$
44. Smedby KE, Akerman M, Hildebrand H, Glimelius B, Ekbom A, Askling J (2005) Malignant lymphomas in coeliac disease: evidence of increased risks for lymphoma types other than enteropathy-type T cell lymphoma. Gut 54:54-59

45. Knight A, Ekbom A, Brandt L, Askling J (2006) Increasing incidence of Wegener's granulomatosis in Sweden, 1975-2001. J Rheumatol 33:2060-2063

46. Hemminki K, Li X, Sundquist J, Hillert J, Sundquist K (2009) Risk for multiple sclerosis in relatives and spouses of patients diagnosed with autoimmune and related conditions. Neurogenetics 10:5-11

47. Risch N (2001) The genetic epidemiology of cancer: interpreting family and twin studies and their implications for molecular genetic approaches. Cancer Epidemiol Biomarkers Prev 10:733-741

48. Hemminki K, Lorenzo Bermejo J (2007) Constraints for genetic association studies imposed by attributable fraction and familial risk. Carcinogenesis 28:648-656

49. Wang WY, Todd JA (2003) The usefulness of different density SNP maps for disease association studies of common variants. Hum Mol Genet 12:3145-3149

50. Hemminki K, Forsti A, Lorenzo Bermejo J (2008) The 'common disease-common variant' hypothesis and familial risk. PLoS ONE 3:e2504 